\title{
Impaired Adipose Tissue Development in Mice With Inactivation of Placental Growth Factor Function
}

\author{
H. Roger Lijnen, ${ }^{1}$ Valerie Christiaens, ${ }^{1}$ Ilse Scroyen, ${ }^{1}$ Gabor Voros, ${ }^{1}$ Marc Tjwa, ${ }^{2}$ Peter Carmeliet,${ }^{2}$ \\ and Désiré Collen ${ }^{1,2}$
}

\begin{abstract}
$\overline{\text { Placental growth factor (PIGF)-deficient }\left(\text { PIGF }^{-\prime-}\right) \text { and }}$ wild-type mice were kept on a standard-fat or high-fat diet for 15 weeks. With the standard-fat diet, the body weights of $\mathrm{PlGF}^{-1-}$ and wild-type mice were comparable, whereas the combined weight of subcutaneous and gonadal adipose tissues was lower in $\operatorname{PIGF}^{-1-}$ mice $(P=0.02)$. With the high-fat diet, PIGF ${ }^{-1-}$ mice had a lower body weight $(P<$ 0.05 ) and less total subcutaneous plus gonadal adipose tissue $(P<0.0001)$. Blood vessel size was lower in gonadal adipose tissue of $\mathrm{PlGF}^{-/-}$mice with both the standard-fat and high-fat diet $(P<0.05)$. Blood vessel density, normalized to adipocyte number, was significantly lower in subcutaneous adipose tissue of $\mathrm{PIGF}^{-/-}$mice fed the high-fat $\operatorname{diet}(P<0.01)$. De novo adipose tissue development in nude mice injected with 3 T3-F442A preadipocytes was reduced $(P<0.005)$ by administration of a PIGF-neutralizing antibody. Bone marrow transplantation from wildtype or $\mathrm{PlGF}^{-/-}$mice to wild-type or $\mathrm{PlGF}^{-/-}$recipient mice revealed significantly lower blood vessel density in PIGF $^{-/-}$recipient mice without an effect on adipose tissue growth. Thus, in murine models of diet-induced obesity, inactivation of PIGF impairs adipose tissue development, at least in part as a result of reduced angiogenesis. Diabetes 55:2698-2704, 2006
\end{abstract}

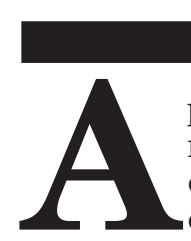

pproximately $50-60 \%$ of the adult population in most industrialized countries are overweight or obese $(1,2)$. Overweight and obesity are considered to be major risk factors for development of the metabolic syndrome and associated cardiovascular disease (2-4).

Adipose tissue, unlike most other organs, grows and develops continuously throughout life. Its development involves extracellular matrix proteolysis, adipogenesis, and angiogenesis (5). Several observations suggested that adipogenesis may be regulated by factors that drive angio-

From the ${ }^{1}$ Center for Molecular and Vascular Biology, Katholieke Universiteit Leuven, Leuven, Belgium; and the ${ }^{2}$ Center for Transgene Technology and Gene Therapy, Flanders Interuniversity Institute for Biotechnology, Katholieke Universiteit Leuven, Leuven, Belgium.

Address correspondence and reprint requests to H.R. Lijnen, Center for Molecular and Vascular Biology, KU Leuven, Campus Gasthuisberg, O \& N 1, Box 911, Herestraat 49, B-3000 Leuven, Belgium. E-mail: roger.lijnen@med. kuleuven.be.

Received for publication 19 April 2006 and accepted in revised form 11 July 2006.

BMT, bone marrow transplantation; ELISA, enzyme-linked immunosorbent assay; mAb, monoclonal antibody; PIGF, placental growth factor; VEGF, vascular endothelial growth factor; VEGFR, VEGF receptor.

DOI: $10.2337 / \mathrm{db} 06-0526$

(C) 2006 by the American Diabetes Association.

The costs of publication of this article were defrayed in part by the payment of page charges. This article must therefore be hereby marked "advertisement" in accordance with 18 U.S.C. Section 1734 solely to indicate this fact. genesis (5-9). Studies in mice suggested that control of the vasculature through inhibition of angiogenesis may impair adipose tissue accretion (6-8).

It is widely accepted that vascular endothelial growth factor (VEGF) accounts for much of the angiogenic activity of adipose tissue (9). VEGF regulates angiogenesis by interacting with two tyrosine kinase receptors, VEGF receptor 1 (VEGFR-1 or Flt-1) and VEGF receptor 2 (VEGFR-2 or Flk-1) (10). A homologue of VEGF was discovered in human placenta and called placental growth factor (PIGF) (11). PlGF is, in fact, produced by many cell types, including adipocytes (12). Different isoforms of PIGF have been identified, of which only PIGF-2 is present in the mouse. PlGF specifically binds Flt-1 and not Flk-1 (13), but its binding to Flt-1 stimulates a cross-talk between both receptors, thereby amplifying Flk-1-driven angiogenesis $(14,15)$.

Because of its expression in adipose tissue, its functional homology with VEGF, and its interaction with VEGFRs, we investigated in the present study whether PIGF may play a role in adipose tissue-related angiogenesis and in control of fat mass.

\section{RESEARCH DESIGN AND METHODS}

Male wild-type or PlGF-deficient $\left(\mathrm{PlGF}^{-1-}\right)$ mice (both with genetic background 50\% Swiss and 50\% 129SV) were obtained as described elsewhere (16). Wild-type and $o b / o b$ mice (both 100\% C57BL/6) were generated in the animal facility of the Molecular Cardiovascular Medicine Group (KU Leuven, Leuven, Belgium). Nude (BALB/c) mice were purchased from Charles River Laboratories (Wilmington, MA). Mice were kept in microisolation cages on a 12-h day-night cycle and fed water and a standard-fat diet (KM-04-k12, containing $13 \% \mathrm{kcal}$ as fat, with a caloric value of $10.9 \mathrm{~kJ} / \mathrm{g}$; Muracon; Carfil) or a high-fat diet (TD88137, containing $42 \% \mathrm{kcal}$ as fat with a caloric value of $20.1 \mathrm{~kJ} / \mathrm{g}$; Harlan Teklad, Madison, WI). Mice were weighed every week, and food intake was measured for 24-h periods throughout the experimental period. Physical activity was evaluated using cages equipped with a turning wheel linked to a computer to register full turning cycles.

At the end of the experiments, after overnight fasting, total body fat was determined by noninvasive densitometry (PIXImus densitometer; Lunar, Madison, WI). The interassay coefficients of variation for the determination of body fat and bone weight were 2.6 and $0.40 \%$, respectively. Lean body mass is given as the difference between body weight and weight of bones and fat tissues. The mice were killed by intraperitoneal injection of $60 \mathrm{mg} / \mathrm{kg}$ sodium pentobarbital (Nembutal; Abbott Laboratories, North Chicago, IL), and blood was collected from the retroorbital sinus on trisodium citrate (final concentration $0.01 \mathrm{~mol} / \mathrm{l}$ ), and plasma was stored at $-20^{\circ} \mathrm{C}$. Intra-abdominal (gonadal) and inguinal subcutaneous fat pads were removed and weighed; portions were immediately frozen at $-80^{\circ} \mathrm{C}$ for protein or RNA extraction and other portions were used to prepare $10-\mu \mathrm{m}$ paraffin sections for histological analysis. Other organs, including pancreas, spleen, kidneys, liver, heart, and lungs, were also removed and weighed. All animal experiments were approved by the local ethical committee (Project P03112) and performed in accordance with the guiding principles of the American Physiological Society and the International Society on Thrombosis and Hemostasis (17). 
TABLE 1

Effect of PlGF deficiency on body and tissue weights after 15 weeks of a standard-fat diet or a high-fat diet

\begin{tabular}{|c|c|c|c|c|}
\hline & \multicolumn{2}{|c|}{ Standard-fat diet } & \multicolumn{2}{|c|}{ High-fat diet } \\
\hline & Wild type & $\mathrm{PlGF}^{-/-}$ & Wild type & $\mathrm{PlGF}^{-/-}$ \\
\hline$n$ & 21 & 19 & 10 & 10 \\
\hline Body $(\mathrm{g})^{*}$ & $38 \pm 1.4$ & $38 \pm 1.0$ & $57 \pm 1.4$ & $49 \pm 3.1 \dagger$ \\
\hline Subcutaneous fat (mg) & $910 \pm 80$ & $460 \pm 61 \ddagger$ & $2,850 \pm 110$ & $1,550 \pm 230 \ddagger$ \\
\hline Gonadal fat (mg) & $1,050 \pm 120$ & $860 \pm 120$ & $1,740 \pm 68$ & $1,350 \pm 180$ \\
\hline Liver (mg) & $1,470 \pm 46$ & $1,390 \pm 49$ & $3,430 \pm 380$ & $2,790 \pm 360$ \\
\hline Pancreas (mg) & $250 \pm 14$ & $270+20$ & $290 \pm 18$ & $320 \pm 29$ \\
\hline Spleen (mg) & $96 \pm 5.8$ & $120 \pm 7.2$ & $160 \pm 8.0$ & $180 \pm 22$ \\
\hline
\end{tabular}

Data are means $\pm \mathrm{SE}$. *Body weight after overnight fasting. $\dagger P<0.05$ and $\ddagger P<0.0005$ vs. wild type.

Assays. The mean adipocyte size was determined by computer-assisted image analysis of adipose tissue sections stained with hematoxylin and eosin or with biotinylated Bandeiraea (Griffonia) simplicifolia BSI lectin (Sigma-Aldrich, Bornem, Belgium) followed by signal amplification with the Tyramide Signal Amplification Cyanine system (Perkin Elmer, Boston, MA). For each animal, three to five areas in four different sections each were analyzed; the data were first averaged per section and then per animal. The lectin staining also visualizes blood vessels (18); average blood vessel size is calculated by dividing the total stained area by the number of vessels, and blood vessel density is expressed as the number of vessels per measured surface area (9-12 sections were analyzed per animal and results were then averaged). Immunostaining for PlGF was performed using rat anti-mouse PlGF-2 mAb465 (R\&D Systems, Lille, France).

Extraction of adipose tissues was performed as described (19), and the protein concentration of the supernatants was determined using the BCA protein assay. Insulin (Mercodia, Uppsala, Sweden), leptin (R\&D Systems), PIGF (R\&D Systems), and endoglin (CD105, a marker of neovascularization [20]) (R\&D Systems) antigen levels were determined with commercially available enzyme-linked immunosorbent assays (ELISAs). Blood glucose concentrations were measured using Glucocard strips (Menarini Diagnostics, Florence, Italy); triglyceride and total, HDL, and LDL cholesterol levels were evaluated using routine clinical assays.

For mRNA determination, subcutaneous and gonadal fat pads were homogenized using lysing matrix tubes (Qbiogene, Carlsbad, CA) in a Hybaid Ribolyser (Thermo, Waltham, MA). Total DNA-free RNA was extracted using an RNeasy kit (Qiagen, Valencia, CA), and the concentration was determined using a RiboGreen RNA quantification kit (Molecular Probes, Eugene, OR). PlGF, VEGF-A121, VEGF-A165, VEGF-A189, Flt-1, and leptin mRNA levels were determined by quantitative RT-PCR and normalized to $18 \mathrm{~S}$ rRNA, as described previously (12).

In vivo experiments. To study the effect of PlGF deficiency on adipose tissue development, 5-week-old male wild-type or $\mathrm{PlGF}^{-/-}$mice were fed a standardfat or high-fat diet for 15 weeks and analyzed as described above. In all four groups, mice of at least four different breeding couples were used.

To evaluate the effect of PIGF neutralization on adipose tissue development, mice were injected with the PIGF neutralizing monoclonal antibody PL5D11D4, which blocks binding to Flt-1 (21) or with the control monoclonal antibody $1 \mathrm{C} 8$, which is directed against human tissue plasminogen activator. The monoclonal antibodies (mAbs) were screened for the absence of endotoxins and were injected three times per week intraperitoneally at a dose of 1 mg per mouse. Three different models were studied: 1) 5-week-old male wild-type (C57BL/6) mice were fed a high-fat diet for 7 weeks and then were injected with the mAbs during 6 weeks; 2) 5-week-old male ob/ob and corresponding wild-type (C57BL/6) mice were fed a high-fat diet and injected with the mAbs during 5 weeks; 3) 5-week-old male nude mice (BALB/c) were injected subcutaneous in the back with $1 \times 10^{7} 3 \mathrm{~T} 3-\mathrm{F} 442 \mathrm{~A}$ preadipocytes, cultured, and characterized as described elsewhere $(22,23)$, to induce de novo adipose tissue formation $(24,25)$. These mice were then fed a high-fat diet, and mAbs were injected during 5 weeks. In all three studies, the mice were monitored, killed, and analyzed as described above.

To monitor the potential recruitment of bone marrow-derived precursor cells to adipose tissue, bone marrow transplantation (BMT) was performed using 5-week-old male wild-type and $\mathrm{PlGF}^{-1-}$ mice. The recipient mice were lethally irradiated with an X-ray source at a single dose rate of 9.5 Gy (26). Bone marrow was aseptically removed from the femoral bone of wild-type or $\mathrm{PlGF}^{-1-}$ mice by flushing with medium (RPMI-1640 medium, 10 units/ml heparin and $2 \%$ fetal bovine serum) and washing with the RPMI-1640 medium. About $5 \times 10^{6}$ cells suspended in $200 \mu$ l of RPMI-1640 medium were injected into the tail vein of the recipient mice. The recipient mice were divided into four groups; wild-type and $\mathrm{PlGF}^{-/-}$mice received either bone marrow from a wild-type littermate or from a $\mathrm{PlGF}^{-/-}$littermate. After the transplantation, the mice were kept in sterile cages, fed water and a high-fat diet for 16 weeks, and analyzed as described above.

Statistical analysis. Data are expressed as means \pm SE. Statistical significance for differences between groups was analyzed by nonparametric $t$ testing. Correlations between groups are evaluated by the Spearman rank test. Progress curves of body weight or weight gain versus time were analyzed by repeated-measures ANOVA. Significance is set at $P<0.05$.

\section{RESULTS}

Effect of PIGF deficiency on adipose tissue development

PlGF${ }^{-/-}$and wild-type mice fed a standard-fat diet. At birth, the body weight of $\mathrm{PlGF}^{-1-}$ pups (two litters) $(n=10)$ was already significantly lower than that of wild-type mice $(n=8)(1.53 \pm 0.06$ vs. $1.79 \pm 0.05 \mathrm{~g})(P=$ $0.008)$. The placenta weights after 18.5 days of pregnancy (from three mice) were $0.12 \pm 0.009 \mathrm{~g}(n=17)$ for wild-type mice compared with $0.096 \pm 0.008 \mathrm{~g}(n=20)$ for $\mathrm{PlGF}^{--}$mice $(P=0.04)$.

When kept fed a standard-fat diet for 15 weeks, $\mathrm{PlGF}^{-1-}$ mice $(n=19)$ had body weights comparable to those of the wild-type controls $(n=21)(42 \pm 1.4$ vs. $41 \pm 1.2 \mathrm{~g})$. After overnight fasting, body weights were still comparable for both genotypes, whereas the subcutaneous $(P<$ $0.0005)$ and gonadal ( $P=\mathrm{NS}$ ) adipose tissue weight was lower for $\mathrm{PlGF}^{-/-}$mice (Table 1). The combined weight of the subcutaneous and gonadal fat pads was significantly lower for PlGF ${ }^{-/-}$mice $(1,315 \pm 166$ vs. $1,954 \pm 200 \mathrm{mg}$, $P=0.025)$. Furthermore, total body fat determined by noninvasive densitometry was significantly lower in $\mathrm{PlGF}^{-/-}$mice $(18 \pm 1.5 \% ; n=6$; body weight $40 \pm 0.9 \mathrm{~g})$ than in wild-type mice ( $34 \pm 3.1 \% ; n=6$; body weight $43 \pm$ $2.9 \mathrm{~g})(P=0.004)$, whereas the lean body mass was higher $(30 \pm 0.94$ vs. $25 \pm 0.82 \mathrm{~g} ; P=0.004)$. The weights of other organs, including liver, spleen, and pancreas, were comparable (Table 1).

Food intake was $5.9 \pm 0.16 \mathrm{~g} \cdot \mathrm{mouse}^{-1} \cdot \mathrm{day}^{-1}$ for wild-type and $6.4 \pm 0.16 \mathrm{~g} /$ day for $\mathrm{PlGF}^{-/-}$mice $(P=$ 0.04). Physical activity at night was comparable $(23,400 \pm$ 360 cycles $/ 12 \mathrm{~h}$ for wild-type vs. $23,000 \pm 1,080$ for $\mathrm{PlGF}^{-/-}$mice).

Adipocyte size was somewhat, but not significantly, lower in subcutaneous and gonadal adipose tissues of $\mathrm{PlGF}^{-1-}$ compared with wild-type mice. Blood vessel size was significantly lower in gonadal but not in subcutaneous adipose tissue of $\mathrm{PlGF}^{-/-}$mice. Blood vessel density was somewhat higher, but this difference largely disappeared after normalization to the adipocyte number (ratio of 0.97 or 0.83 for subcutaneous adipose tissue of $\mathrm{PlGF}^{-/-}$or wild-type mice, respectively, with corresponding values of 0.77 for gonadal adipose tissue of both genotypes) (Table 
TABLE 2

Effect of PlGF deficiency on adipocyte and blood vessel size and density in adipose tissue after 15 weeks of a standard-fat or high-fat diet

\begin{tabular}{|c|c|c|c|c|}
\hline & \multicolumn{2}{|c|}{ Standard-fat diet } & \multicolumn{2}{|c|}{ High-fat diet } \\
\hline & Wild type & $\mathrm{PlGF}^{-/-}$ & Wild type & $\mathrm{PlGF}^{-/-}$ \\
\hline$n$ & 15 & 11 & 10 & 10 \\
\hline \multicolumn{5}{|l|}{ Adipocyte size $\left(\mu \mathrm{m}^{2}\right)$} \\
\hline Subcutaneous fat & $1,260 \pm 130$ & $1,050 \pm 280$ & $2,900 \pm 120$ & $2,240 \pm 280$ \\
\hline Gonadal fat & $1,590 \pm 180$ & $1,280 \pm 280$ & $3,400 \pm 190$ & $2,590 \pm 360$ \\
\hline \multicolumn{5}{|c|}{ Adipocyte density $\left(\times 10^{-6} / \mu \mathrm{m}^{2}\right)$} \\
\hline Subcutaneous fat & $670 \pm 57$ & $740 \pm 97$ & $264 \pm 9.2$ & $470 \pm 92 *$ \\
\hline Gonadal fat & $510 \pm 66$ & $580 \pm 75$ & $240 \pm 16$ & $400 \pm 66 \dagger$ \\
\hline \multicolumn{5}{|c|}{ Blood vessel size $\left(\mu \mathrm{m}^{2}\right)$} \\
\hline Subcutaneous fat & $17 \pm 1.0$ & $19 \pm 1.0$ & $28 \pm 2.4$ & $25 \pm 1.7$ \\
\hline Gonadal fat & $27 \pm 1.7$ & $20 \pm 2.2 \dagger$ & $41 \pm 3.1$ & $30 \pm 2.2 \dagger$ \\
\hline \multicolumn{5}{|c|}{ Blood vessel density $\left(\times 10^{-6} / \mu \mathrm{m}^{2}\right)$} \\
\hline Subcutaneous fat & $540 \pm 42$ & $700 \pm 97$ & $320 \pm 15$ & $430 \pm 57$ \\
\hline Gonadal fat & $370 \pm 37$ & $410 \pm 53$ & $290 \pm 23$ & $350 \pm 44$ \\
\hline \multicolumn{5}{|c|}{ Normalized blood vessel density } \\
\hline Subcutaneous fat & $0.83 \pm 0.053$ & $0.97 \pm 0.073$ & $1.22 \pm 0.045$ & $0.96 \pm 0.036^{*}$ \\
\hline Gonadal fat & $0.77 \pm 0.035$ & $0.77 \pm 0.056$ & $1.21 \pm 0.096$ & $0.96 \pm 0.087$ \\
\hline
\end{tabular}

Data are means $\pm \mathrm{SE} . * P=0.01$ and $† P<0.05$ vs. wild type.

2). Endoglin levels in adipose tissue extracts were comparable for wild-type and $\mathrm{PlGF}^{-/-}$mice $(140 \pm 37$ vs. $130 \pm$ $42 \mathrm{ng} / \mathrm{g}$ subcutaneous adipose tissue and $150 \pm 35 \mathrm{vs}$. $160 \pm 36 \mathrm{ng} / \mathrm{g}$ gonadal adipose tissue).

Metabolic parameters, including glucose, insulin, total cholesterol, HDL cholesterol, LDL cholesterol, and triglycerides, were also comparable for $\mathrm{PlGF}^{-\prime-}$ and wild-type mice fed a standard-fat diet (not shown). However, leptin levels were significantly lower in the PlGF ${ }^{-1-}$ mice $(6.3 \pm$ $2.9 \mathrm{ng} / \mathrm{ml}[n=11]$ vs. $15 \pm 2.5 \mathrm{ng} / \mathrm{ml}[n=15] ; P<0.005)$. Leptin levels correlated with subcutaneous adipose tissue mass in both wild-type $(r=0.77, P<0.0001)$ and $\mathrm{PlGF}^{-/-}$ $(r=0.80, P<0.0001)$ mice; a correlation with gonadal adipose tissue mass was observed only in the wild-type mice $(r=0.77, P<0.0001)$.

After 15 weeks of a standard-fat diet, expression of PIGF mRNA in gonadal adipose tissue was three- to fourfold higher than in subcutaneous adipose tissue in wild-type mice. PIGF antigen levels in adipose tissue extracts were, however, below the detection limit of the ELISA $(<6$ $\mathrm{ng} / \mathrm{mg}$ protein). Expression of isoforms VEGF-A121, VEGF-A165, and VEGF-A189 was comparable in subcutaneous adipose tissue of both genotypes but was higher in gonadal adipose tissue of $\mathrm{PlGF}^{-/-}$mice. Flt-1 expression levels were not different (Table 3).

PIGF $^{-/-}$and wild-type mice fed a high-fat diet. At the start of the diet (5 weeks of age), the body weights of the
$\mathrm{PlGF}^{-/-}$and wild-type mice were comparable ( $29 \pm 0.9 \mathrm{vs}$. $28 \pm 0.8 \mathrm{~g} ; n=10$ ). When fed a high-fat diet for 15 weeks, $\mathrm{PlGF}^{-i-}$ mice gained less weight then wild-type controls $(24 \pm 2.9$ vs. $34 \pm 1.2 \mathrm{~g} ; P<0.005)$, resulting in significantly lower body weight ( $53 \pm 3.0$ vs. $62 \pm 1.5$ g; $P<0.05$ ) (Fig. 1). Repeated-measures ANOVA confirmed that both genotypes react significantly differently to the high-fat diet $(P<0.000001)$. After overnight fasting, the weight difference remained $(P<0.05)$, and the weights of the isolated subcutaneous $(P<0.0005)$ or gonadal $(P=$ NS) fat pads were lower in the $\mathrm{PlGF}^{-1-}$ group (Table 1). The combined weights of the subcutaneous and gonadal fat pads were significantly lower for $\mathrm{PlGF}^{-/-}$mice $(2,901 \pm 371 \mathrm{vs}$. $4,588 \pm 158 \mathrm{mg}, P<0.0001)$.

Food intake was comparable for both genotypes $(4.8 \pm$ 0.15 or $4.5 \pm 0.13 \mathrm{~g} \cdot$ mouse $^{-1} \cdot$ day $^{-1}$ for wild-type or $\mathrm{PlGF}^{-/-}$mice, corresponding to $86 \pm 4.6$ or $82 \pm 3.2 \mathrm{mg}$. day $^{-1} \cdot \mathrm{g}$ body $\mathrm{wt}^{-1}$, respectively) and was relatively constant during the diet period. Physical activity at night was comparable for wild-type and $\mathrm{PlGF}^{-1-}$ mice fed a high-fat diet $(20,100 \pm 260$ vs. $19,600 \pm 1,200$ cycles/12 h).

Adipocytes and blood vessels were somewhat smaller in $\mathrm{PlGF}^{-/-}$mice (Fig. 2 and Table 2). When the blood vessel density was normalized to the adipocyte number in the tissue, it was lower in the adipose tissues of $\mathrm{PlGF}^{-/-}$ compared with wild-type mice (ratio of 0.96 vs. $1.22[P=$ $0.001]$ for subcutaneous and 0.96 vs. $1.21[P=0.09]$ for

TABLE 3

mRNA expression levels in subcutaneous and gonadal adipose tissue of mice kept on a standard-fat or high-fat diet for 15 weeks

\begin{tabular}{|c|c|c|c|c|c|c|c|c|}
\hline & \multicolumn{4}{|c|}{ Standard-fat diet } & \multicolumn{4}{|c|}{ High-fat diet } \\
\hline & \multicolumn{2}{|c|}{ Wild type } & \multicolumn{2}{|c|}{$\mathrm{PlGF}^{-/-}$} & \multicolumn{2}{|c|}{ Wild type } & \multicolumn{2}{|c|}{$\mathrm{PlGF}^{-/-}$} \\
\hline & Subcutaneous & Gonadal & Subcutaneous & Gonadal & Subcutaneous & Gonadal & Subcutaneous & Gonadal \\
\hline $\mathrm{PlGF}$ & 4.6 & 18 & $\mathrm{ND}$ & ND & 8.9 & 15 & ND & $\mathrm{ND}$ \\
\hline VEGF-A121 & 12 & 13 & 12 & 25 & 5.2 & 5.9 & 7.3 & 11 \\
\hline VEGF-A165 & 15 & 13 & 17 & 30 & 3.9 & 5.6 & 6.6 & 11 \\
\hline VEGF-A189 & 3.6 & 2.0 & 3.4 & 10 & 1.9 & 3.4 & 2.7 & 5.1 \\
\hline Flt-1 & 10 & 12 & 10 & 12 & 9.2 & 10 & 9.2 & 10 \\
\hline Leptin & 1.8 & 1.6 & 2.4 & 5.5 & 4.9 & 8.0 & 3.9 & 6.1 \\
\hline
\end{tabular}

Data are normalized to $18 \mathrm{~S}$ rRNA and represent pools of 10 samples measured in duplicate in two determinations. ND, not detected. 
A

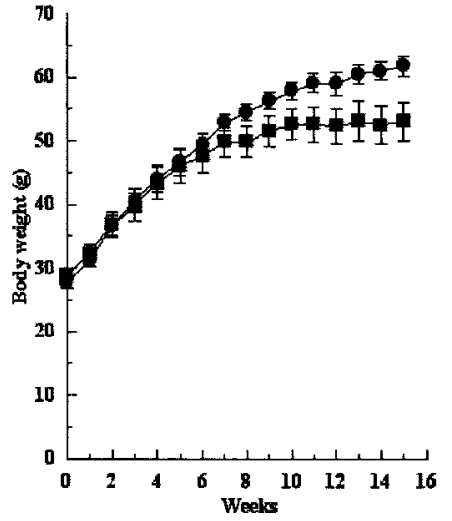

B

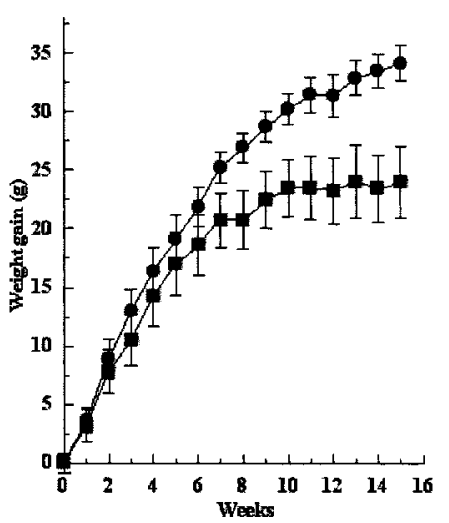

FIG. 1. Body weight $(A)$ and weight gain $(B)$ of wild-type $(\bigcirc)$ or PIGF $^{-\prime-}(\square)$ mice fed a high-fat diet for 15 weeks. Data are means \pm SE of 10 experiments.

gonadal adipose tissue). Endoglin levels were also comparable in adipose tissue extracts of wild-type or $\mathrm{PlGF}^{-/-}$ mice (54 \pm 4.4 vs. $74 \pm 22 \mathrm{ng} / \mathrm{g}$ subcutaneous adipose tissue and $79 \pm 9.6$ vs. $68 \pm 18 \mathrm{ng} / \mathrm{g}$ gonadal adipose tissue).

After 15 weeks of high-fat diet, plasma levels of glucose, insulin, total cholesterol, HDL and LDL cholesterol, and triglycerides were not significantly different for wild-type and $\mathrm{PlGF}^{-/-}$mice (not shown). Plasma leptin levels were $54 \pm 13 \mathrm{ng} / \mathrm{ml}$ for $\mathrm{PlGF}^{-/-}$mice compared with $83 \pm 7.6$ $\mathrm{ng} / \mathrm{ml}$ for wild-type mice $(P=0.10)$. Leptin mRNA expression was somewhat higher in gonadal than in subcutaneous adipose tissue but was comparable for wild-type and $\mathrm{PlGF}^{-/-}$mice (Table 3 ).

PlGF mRNA was detected in both subcutaneous and gonadal adipose tissue of wild-type mice fed the high-fat diet for 15 weeks (at an approximate twofold higher level
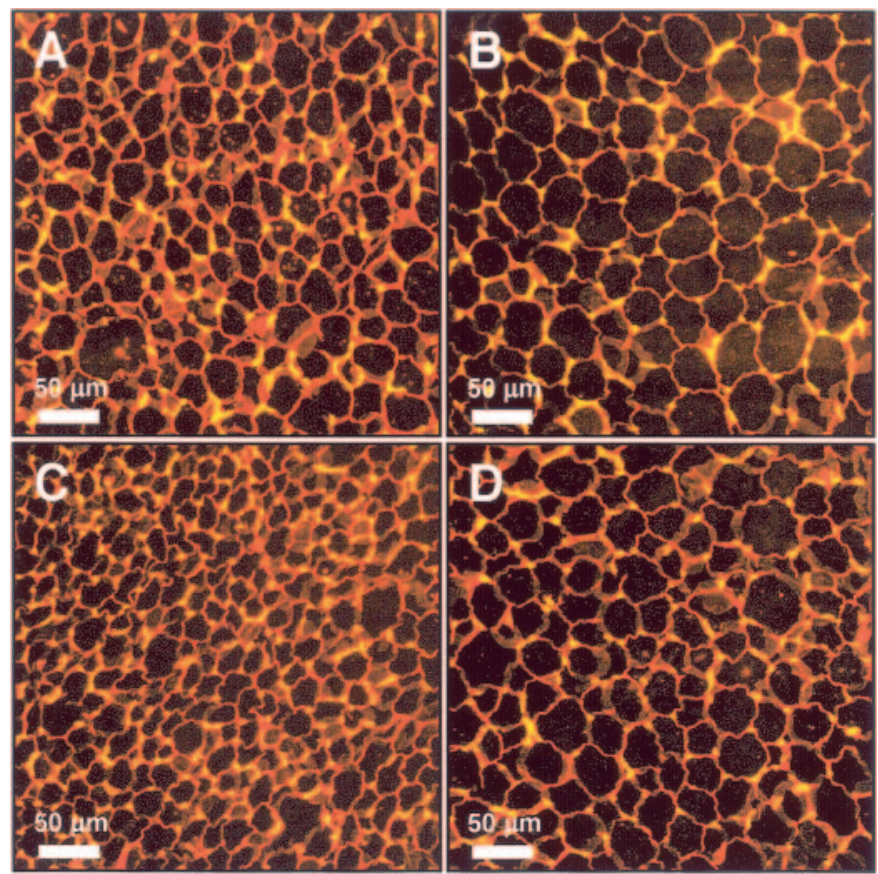

FIG. 2. Staining with the $B$. simplicifolia lectin of subcutaneous adipose tissue from wild-type $(A$ and $B)$ or $\mathrm{PlGF}^{-/-}(C$ and $D)$ mice fed a standard-fat diet ( $A$ and $C$ ) or a high-fat diet $(B$ and $D$ ) for 15 weeks. The yellow structures are blood vessels.

in gonadal tissue) (Table 3). Immunostaining with a rat anti-mouse PlGF-2 mAb confirmed expression of PlGF in wild-type adipose tissues (not shown). PlGF antigen levels in adipose tissue extracts were, however, undetectable by ELISA. Expression of the isoforms VEGF-A121 and VEGFA165 was approximately twofold higher in gonadal adipose tissue of $\mathrm{PlGF}^{-/-}$mice compared with wild-type controls. Expression of Flt-1 was comparable in subcutaneous and gonadal adipose tissue of both genotypes (Table 3).

Effect of PIGF neutralization on adipose tissue development. Administration of the PlGF-neutralizing mAb PL5D11D4 or the control mAb $1 \mathrm{C} 8$ to 12 -week-old wildtype mice ( $n=10$ each) fed a high-fat diet for 6 weeks resulted in very similar body weights (38 \pm 0.9 vs. $38 \pm$ $1.5 \mathrm{~g})$ and weights of the isolated subcutaneous (1,510 \pm 80 vs. $1,500 \pm 57 \mathrm{mg})$ or gonadal $(2,100 \pm 60$ vs. $2,160 \pm 88$ mg) adipose tissues after 6 weeks of administration. Leptin levels in adipose tissue extracts were comparable for mAb PL5D11D4- and mAb 1C8-treated mice, both in subcutaneous ( $80 \pm 8.5$ vs. $83 \pm 10 \mathrm{ng} / \mathrm{g}$ tissue) and in gonadal ( $65 \pm 15$ vs. $66 \pm 9.6 \mathrm{ng} / \mathrm{g}$ tissue) adipose tissue.

Similarly, administration of mAb PL5D11D4 or mAb 1C8 during 5 weeks to 5 -week-old $o b / o b$ mice $(n=8$ or 7$)$ or to corresponding wild-type mice ( $n=9$ or 8 ) resulted in comparable body weights $(46 \pm 1.4 \mathrm{vs} .47 \pm 1.7 \mathrm{~g}$ for $\mathrm{ob} / \mathrm{ob}$ and $26 \pm 0.80$ vs. $26 \pm 0.75$ g for wild type), and weights of isolated subcutaneous $(2,990 \pm 120 \mathrm{vs}$. 3,270 $\pm 220 \mathrm{mg}$ for $o b / o b$ and $510 \pm 120$ vs. $430 \pm 75 \mathrm{mg}$ for wild type) and gonadal $(3,040 \pm 200$ vs. $3,030 \pm 160 \mathrm{mg}$ for $o b / o b$ and $610 \pm 75$ vs. $610 \pm 99 \mathrm{mg}$ for wild type) adipose tissues after 5 weeks of administration. In both models, food intake was not different for the two mAbs; adipocyte and blood vessel size and density in the adipose tissues was not significantly different, and weights of other organs including liver, kidney, spleen, pancreas, lung, and heart were comparable (data not shown).

Administration of mAb PL5D11D4 during 5 weeks to nude mice previously injected with 3T3-F442A preadipocytes, in contrast, caused a significant reduction of the de novo fat pad formation compared with mice receiving the control mAb $1 \mathrm{C} 8(14 \pm 2.5 \mathrm{mg}[n=10] \mathrm{vs} .27 \pm 3.6 \mathrm{mg}$ $[n=6], P=0.0047)$. In the mAb PL5D11D4- and mAb $1 \mathrm{C} 8$-treated groups, total body weights ( $25 \pm 0.45$ vs. $24 \pm$ $0.25 \mathrm{~g})$ and weights of the isolated subcutaneous (267 \pm 33 vs. $283 \pm 17 \mathrm{mg}$ ) or gonadal (276 $\pm 58 \mathrm{vs} .314 \pm 17 \mathrm{mg})$ adipose tissues were indistinguishable. Quantitative analysis of the fat pads (Table 4) revealed comparable adipocyte size and density for both mAbs, whereas the blood vessel size was somewhat smaller in de novo, subcutaneous, and gonadal adipose tissues of the mAb PL5D11D4treated mice. Blood vessel densities, normalized to adipocyte number, were, however, not different. The weight of other organs was also very similar.

Effect of BMT on adipose tissue development. High-fat diet feeding for 16 weeks after BMT of wild-type or $\mathrm{PlGF}^{-/-}$donor to wild-type or $\mathrm{PlGF}^{-/-}$recipient mice produced $\sim 25 \%$ lower weight gain in the $\mathrm{PlGF}^{-1-}$ recipient mice (Table 5). Weights of the isolated subcutaneous and gonadal adipose tissues, as well as the adipocyte and blood vessel size, were comparable. However, blood vessel densities before and after normalization to adipocyte number were significantly lower in the $\mathrm{PlGF}^{-1-}$ recipient mice, both for BMT (wild type $\rightarrow \mathrm{PlGF}^{-/-}$) and for BMT $\left(\mathrm{PlGF}^{-/-} \rightarrow \mathrm{PlGF}^{-/-}\right)$. For BMT $\left(\mathrm{PlGF}^{-/-} \rightarrow\right.$ wild type $)$ 
TABLE 4

Effect of PlGF neutralization on adipocyte and blood vessel size and density in adipose tissues after injection of 3T3-F442A preadipocytes into nude mice

\begin{tabular}{|c|c|c|c|c|c|c|}
\hline & \multicolumn{3}{|c|}{ mAb PL5D11D4 } & \multicolumn{3}{|c|}{ mAb $1 \mathrm{C} 8$} \\
\hline & De novo & Subcutaneous & Gonadal & De novo & Subcutaneous & Gonadal \\
\hline Adipoctyte size $\left(\mu \mathrm{m}^{2}\right)$ & $1,200 \pm 110$ & $720 \pm 110$ & $1,140 \pm 93$ & $1,440 \pm 93$ & $730 \pm 35$ & $1,260 \pm 88$ \\
\hline Adipocyte density $\left(\times 10^{-6} / \mu \mathrm{m}^{2}\right)$ & $620 \pm 34$ & $1,090 \pm 120$ & $710 \pm 56$ & $550 \pm 23$ & $1,000 \pm 20$ & $620 \pm 27$ \\
\hline Blood vessel size $\left(\mu \mathrm{m}^{2}\right)$ & $27 \pm 3.9$ & $27 \pm 5.5$ & $19 \pm 2.5$ & $33 \pm 4.6$ & $30 \pm 2.3$ & $24 \pm 3.2$ \\
\hline Blood vessel density $\left(\times 10^{-6} / \mu \mathrm{m}^{2}\right)$ & $1,160 \pm 68$ & $1,260 \pm 130$ & $880 \pm 64$ & $1,010 \pm 120$ & $1,160 \pm 72$ & $670 \pm 75$ \\
\hline Normalized blood vessel density & $1.90 \pm 0.11$ & $1.18 \pm 0.05$ & $1.25 \pm 0.07$ & $1.85 \pm 0.19$ & $1.19 \pm 0.05$ & $1.09 \pm 0.11$ \\
\hline
\end{tabular}

Data are means $\pm \mathrm{SE}$.

these data were comparable to those for BMT (wild type $\rightarrow$ wild type) (Table 5).

Successful BMT in this model is confirmed by the fact that the mice survived, whereas control mice without BMT died within 1-2 weeks of the irradiation. Furthermore, blood cell counts were normalized within 4 weeks of the BMT (data not shown).

PlGF mRNA levels, normalized to $28 \mathrm{~S}$ RNA, were comparable in subcutaneous and in gonadal adipose tissues after BMT (wild type $\rightarrow$ wild type) and BMT $\left(\mathrm{PlGF}^{-/-}\right.$ $\rightarrow$ wild type). No PlGF expression was detected in adipose tissues after BMT (wild type $\rightarrow \mathrm{PlGF}^{-/-}$) or BMT $\left(\mathrm{PlGF}^{-/-}\right.$ $\rightarrow \mathrm{PlGF}^{-/-}$) (data not shown).

\section{DISCUSSION}

PlGF is expressed in murine adipose tissue, both in adipocytes and in the stromal-vascular cell fraction (12), but no information on a potential functional role is available. In the present study, we have investigated whether PlGF inactivation affects adipose tissue development in murine models of obesity.

With a standard-fat diet, the total body weights of
$\mathrm{PlGF}^{-/-}$and wild-type mice were comparable; although total body fat content was lower in $\mathrm{PlGF}^{-/-}$mice, their lean body mass was higher. With a high-fat diet, $\mathrm{PlGF}^{-/-}$ mice had significantly reduced body weights and subcutaneous and gonadal fat pad weights. Blood vessel density normalized to the adipocyte number (27) is 1.5- or 1.6-fold higher in subcutaneous or gonadal adipose tissue of obese wild-type mice compared with that of lean controls. In contrast, there is little difference between $\mathrm{PlGF}^{-/-}$lean or obese mice (1.0- or 1.2-fold for subcutaneous or gonadal tissue, respectively). Thus, in obese (15 weeks of a high-fat diet) $\mathrm{PlGF}^{-1-}$ mice, subcutaneous and gonadal adipose tissue blood vessel densities are lower than those in wild-type mice (Table 2), indicating that development of new blood vessels is impaired in the $\mathrm{PlGF}^{-/-}$mice fed a high-fat diet. $\mathrm{PlGF}^{-/-}$mice also showed significantly lower blood vessel size in gonadal adipose tissues, with both a standard-fat and high-fat diet. These findings suggest that impaired angiogenesis in $\mathrm{PlGF}^{-/-}$mice fed a high-fat diet, possibly associated with reduced adipose tissue perfusion, contributes to the reduced adipose tissue growth. In mice fed a standard-fat diet, however, the lower

TABLE 5

Effect of BMT on adipose tissue development

BMT

\begin{tabular}{|c|c|c|c|c|}
\hline & (Wild type $\rightarrow$ wild type) & $\left(\mathrm{PlGF}^{-1-} \rightarrow\right.$ wild type $)$ & (Wild type $\rightarrow \mathrm{PlGF}^{-/-}$) & $\left(\mathrm{PlGF}^{-/-} \rightarrow \mathrm{PlGF}^{-/-}\right)$ \\
\hline$n$ & 7 & 7 & 10 & 9 \\
\hline Weight gain (g) & $13 \pm 1.4$ & $13 \pm 2.1$ & $9.2 \pm 2.5$ & $9.9 \pm 1.4$ \\
\hline \multicolumn{5}{|l|}{ Weight (mg) } \\
\hline Subcutaneous fat & $1,270 \pm 150$ & $1,200 \pm 170$ & $990 \pm 110$ & $840 \pm 130$ \\
\hline Gonadal fat & $1,630 \pm 220$ & $1,390 \pm 230$ & $1,210 \pm 150$ & $1,420 \pm 200$ \\
\hline \multicolumn{5}{|l|}{ Adipocyte size $\left(\mu \mathrm{m}^{2}\right)$} \\
\hline Subcutaneous fat & $1,560 \pm 110$ & $1,790 \pm 250$ & $1,870 \pm 130$ & $1,560 \pm 130$ \\
\hline Gonadal fat & $3,460 \pm 500$ & $3,320 \pm 420$ & $3,150 \pm 310$ & $3,090 \pm 250$ \\
\hline \multicolumn{5}{|l|}{$\begin{array}{l}\text { Adipocyte density } \\
\qquad\left(\times 10^{-6} / \mu \mathrm{m}^{2}\right)\end{array}$} \\
\hline Subcutaneous fat & $540 \pm 30$ & $510 \pm 59$ & $470 \pm 29$ & $540 \pm 38$ \\
\hline Gonadal fat & $270 \pm 29$ & $290 \pm 38$ & $310 \pm 32$ & $300 \pm 27$ \\
\hline \multicolumn{5}{|c|}{ Blood vessel size $\left(\mu \mathrm{m}^{2}\right)$} \\
\hline Subcutaneous fat & $16 \pm 1.3$ & $16 \pm 1.9$ & $15 \pm 0.69$ & $16 \pm 0.69$ \\
\hline Gonadal fat & $26 \pm 3.6$ & $27 \pm 3.2$ & $21 \pm 2.0$ & $21 \pm 0.99$ \\
\hline \multicolumn{5}{|l|}{$\begin{array}{l}\text { Blood vessel density } \\
\left(\times 10^{-6} / \mu \mathrm{m}^{2}\right)\end{array}$} \\
\hline Subcutaneous fat & $370 \pm 16$ & $310 \pm 40$ & $260 \pm 18^{*}$ & $270 \pm 22 \dagger$ \\
\hline Gonadal fat & $240 \pm 22$ & $240 \pm 35$ & $160 \pm 9.0^{*}$ & $180 \pm 16 \ddagger$ \\
\hline \multicolumn{5}{|c|}{$\begin{array}{l}\text { Normalized blood vessel } \\
\text { density }\end{array}$} \\
\hline Subcutaneous fat & $0.73 \pm 0.07$ & $0.63 \pm 0.07$ & $0.55 \pm 0.03$ & $0.52 \pm 0.04 \ddagger$ \\
\hline Gonadal fat & $0.96 \pm 0.11$ & $0.83 \pm 0.05 \S$ & $0.59 \pm 0.07 \dagger$ & $0.65 \pm 0.08 \ddagger$ \\
\hline
\end{tabular}

Data are means $\pm \mathrm{SE} . * P<0.005, \dagger P<0.01$, and $\ddagger P<0.05$ vs. BMT (wild type $\rightarrow$ wild type); $\S P<0.05$ vs. BMT (wild type $\rightarrow$ PlGF ${ }^{-/}-$). 
subcutaneous adipose tissue weight does not seem to be angiogenesis dependent.

Plasma leptin levels were lower in $\mathrm{PlGF}^{-1-}$ than in wild-type mice and correlated with adipose tissue mass, as reported previously (28). This may be due to differences in secretion from adipose tissues or in clearance of leptin. Our finding that leptin levels in subcutaneous and gonadal adipose tissues were not affected by treatment with a PlGF-neutralizing antibody do not support a direct interaction between leptin and PlGF.

De novo fat pad formation in nude mice could be impaired with mAb PL5D11D4. This mAb blocks binding of PlGF to its receptor Flt-1 and was previously successfully used at the same dose in murine models of basal adhesion formation after laparoscopy (21) and in several tumor models (C. Fischer, P.C., unpublished data). In contrast, attempts to reduce adipose tissue development by administration of this mAb to wild-type mice fed a high-fat diet or to $o b / o b$ mice fed a standard-fat diet failed, indicating that direct interactions of PlGF with Flt-1 do not promote ongoing adipose tissue development. Thus, neutralization of PlGF function does not affect ongoing adipose tissue formation but has the capacity to prevent or impair de novo fat pad formation. This finding is in agreement with the observed impaired adipose tissue formation in mice with a genetic deficiency of PlGF. It was previously shown in the same diet model that expression of PlGF, primarily in subcutaneous adipose tissue, decreases with time (between 2 and 15 weeks of diet) (12). It is conceivable that PlGF is mainly important during the first stages of adipose tissue formation, whereas in later phases other angiogenic factors may become more important.

In our model, we did not observe significant effects on adipose tissue formation (during 16 weeks of a high-fat diet) of BMT from wild-type or $\mathrm{PlGF}^{-/-}$donor to wild-type or $\mathrm{PlGF}^{-/-}$recipient mice, although weight gain was consistently lower in $\mathrm{PlGF}^{-/-}$recipient mice. We did observe a significantly lower blood vessel density (Table 5) in adipose tissues of $\mathrm{PlGF}^{-/-}$recipient mice, which is in agreement with the findings in the diet study (Table 2). After BMT, PIGF mRNA was detected only in adipose tissues of mice with BMT (wild type $\rightarrow$ wild type) and $\left(\mathrm{PlGF}^{-/-} \rightarrow\right.$ wild type) but not in mice with BMT (wild type $\rightarrow \mathrm{PlGF}^{-/-}$), indicating that recruitment of precursor cells from bone marrow to adipose tissue does not occur in this model. It is thus conceivable that PIGF derived from adipocytes and/or stromal-vascular cells in the adipose tissue contributes to local angiogenesis.

Our observations are in line with the emerging concept that PlGF deficiency has little or no effect on angiogenesis under normal conditions (as with a standard-fat diet) but is associated with impaired angiogenesis under stress conditions (29-33) (as with a high-fat diet). Thus, reduced angiogenesis during the early stages of adipose tissue development in mice with PlGF deficiency may contribute to impaired obesity.

\section{ACKNOWLEDGMENTS}

This study was supported by grants from the Research Fund, Katholieke Universiteit Leuven (OT 03/48), the Interuniversity Attraction Poles (Project P5/02), and the Flemish Fund for Scientific Research (FWO-Vlaanderen, Project G.0281.04).
Skillful technical assistance by L. Frederix, K. Umans, A. Van Damme, and B. Van Hoef is gratefully acknowledged.

\section{REFERENCES}

1. Rossner S: Obesity: the disease of the twenty-first century. Int J Obes Relat Metab Disord 26 (Suppl. 4):S2-S4, 2002

2. Abelson P, Kennedy D: The obesity epidemic (Editorial). Science 304:1413, 2004

3. Isomaa B, Almgren P, Tuomi T, Forsen B, Lahti K, Nissen M, Taskinen MR, Groop L: Cardiovascular morbidity and mortality associated with the metabolic syndrome. Diabetes Care 24:683-689, 2001

4. Lakka HM, Laaksonen DE, Lakka TA, Niskanen LK, Kumpusalo E, Tuomilehto J, Salonen JT: The metabolic syndrome and total and cardiovascular disease mortality in middle-aged men. JAMA 288:2709-2716, 2002

5. Crandall DL, Hausman GJ, Kral JG: A review of the microcirculation of adipose tissue: anatomic, metabolic, and angiogenic perspectives. Microcirculation 4:211-232, 1997

6. Rupnick MA, Panigrahy D, Zhang CY, Dallabrida SM, Lowell BB, Langer R, Folkman MJ: Adipose tissue mass can be regulated through the vasculature. Proc Natl Acad Sci U S A 99:10730-10735, 2002

7. Fukumura D, Ushiyama A, Duda DG, Xu L, Tam J, Krishna V, Chatterjee K, Garkavtsev I, Jain RK: Paracrine regulation of angiogenesis and adipocyte differentiation during in vivo adipogenesis. Circ Res 93:88-97, 2003

8. Bråkenhielm E, Cao R, Gao B, Angelin B, Cannon B, Parini P, Cao Y: Angiogenesis inhibitor, TNP-470, prevents diet-induced and genetic obesity in mice. Circ Res 94:1579-1588, 2004

9. Hausman GJ, Richardson RL: Adipose tissue angiogenesis. J Anim Sci 82:925-934, 2004

10. Neufeld G, Cohen T, Gengrinovitch S, Poltorak Z: Vascular endothelial growth factor (VEGF) and its receptors. FASEB J 13:9-22, 1999

11. Maglione D, Guerriero V, Viglietto G, Delli-Bovi P, Persico MG: Isolation of a human placenta cDNA coding for a protein related to the vascular permeability factor. Proc Natl Acad Sci U S A 88:9267-9271, 1991

12. Voros G, Maquoi E, Demeulemeester D, Clerx N, Collen D, Lijnen HR: Modulation of angiogenesis during adipose tissue development in murine models of obesity. Endocrinology 146:4545-4554, 2005

13. Park JE, Chen HH, Winer J, Houck KA, Ferrara N: Placenta growth factor potentiation of vascular endothelial growth factor bioactivity, in vitro and in vivo, and high affinity binding to Flt-1 but not to Flk-1/KDR. J Biol Chem 269:25646-25654, 1994

14. Autiero M, Luttun A, Tjwa M, Carmeliet P: Placental growth factor and its receptor, vascular endothelial growth factor receptor-1: novel targets for stimulation of ischemic tissue revascularization and inhibition of angiogenic and inflammatory disorders. J Thromb Haemost 1:1356-1370, 2003

15. Autiero M, Waltenberger J, Communi D, Kranz A, Moons L, Lambrechts D, Kroll J, Plaisance S, De Mol M, Bono F, Kliche S, Fellbrich G, BallmerHofer K, Maglione D, Mayr-Beyrle U, Dewerchin M, Dombrowski S, Stanimirovic D, Van Hummelen P, Dehio C, Hicklin DJ, Persico G, Herbert JM, Shibuya M, Collen D, Conway EM, Carmeliet P: Role of PIGF in the intra- and intermolecular cross talk between the VEGF receptors Flt1 and Flk1. Nat Med 9:936-943, 2003

16. Carmeliet P, Moons L, Luttun A, Vincenti V, Compernolle V, De Mol M, Wu Y, Bono F, Devy L, Beck H, Scholz D, Acker T, DiPalma T, Dewerchin M, Noel A, Stalmans I, Barra A, Blacher S, Vandendriessche T, Ponten A, Eriksson U, Plate KH, Foidart JM, Schaper W, Charnock-Jones DS, Hicklin DJ, Herbert JM, Collen D, Persico MG: Synergism between vascular endothelial growth factor and placental growth factor contributes to angiogenesis and plasma extravasation in pathological conditions. Nat Med 7:575-583, 2001

17. Giles AR: Guidelines for the use of animals in biomedical research. Thromb Haemost 58:1078-1084, 1987

18. Laitinen L: Griffonia simplicifolia lectins bind specifically to endothelial cells and some epithelial cells in mouse tissues. Histochem $J$ 19:225-234, 1987

19. Lijnen HR, Maquoi E, Holvoet P, Mertens A, Lupu F, Morange P, Alessi MC, Juhan-Vague I: Adipose tissue expression of gelatinases in mouse models of obesity. Thromb Haemost 85:1111-1116, 2001

20. Fonsatti E, Sigalotti L, Arslan P, Altomonte M, Maio M: Emerging role of endoglin (CD105) as a marker of angiogenesis with clinical potential in human malignancies. Curr Cancer Drug Targets 3:427-432, 2003

21. Molinas CR, Campo R, Dewerchin M, Eriksson U, Carmeliet P, Koninckx PR: Role of vascular endothelial growth factor and placental growth factor in basal adhesion formation and in carbon dioxide pneumoperitoneumenhanced adhesion formation after laparoscopic surgery in transgenic mice. Fertil Steril 80 (Suppl. 2):803-811, 2003 
22. Green H, Kehinde O: Spontaneous heritable changes leading to increased adipose conversion in 3T3 cells. Cell 7:105-113, 1976

23. Maquoi E, Munaut C, Colige A, Collen D, Lijnen HR: Modulation of the expression of murine matrix metalloproteinases and their tissue inhibitors with obesity. Diabetes 51:1093-1101, 2002

24. Mandrup S, Loftus TM, MacDougald OA, Kuhajda FP, Lane MD: Obese gene expression at in vivo levels by fat pads derived from s.c. implanted 3T3-F442A preadipocytes. Proc Natl Acad Sci U S A 94:4300-4305, 1997

25. Neels JG, Thinnes T, Loskutoff DJ: Angiogenesis in an in vivo model of adipose tissue development. FASEB $J$ 18:983-985, 2004

26. Scholz D, Elsaesser H, Sauer A, Friedrich C, Luttun A, Carmeliet P, Schaper W: Bone marrow transplantation abolishes inhibition of arteriogenesis in placenta growth factor $(\mathrm{PlGF})^{-1-}$ mice. $\mathrm{J} \mathrm{Mol}$ Cell Cardiol 35:177-184, 2003

27. Hlatky L, Hahnfeldt P, Folkman J: Clinical application of antiangiogenic therapy: microvessel density, what it does and doesn't tell us. J Natl Cancer Inst 94:883-893, 2002

28. Maquoi E, Demeulemeester D, Voros G, Collen D, Lijnen HR: Enhanced nutritionally induced adipose tissue development in mice with stromelysin-1 gene inactivation. Thromb Haemost 89:696-704, 2003
29. Tjwa M, Luttun A, Autiero M, Carmeliet P: VEGF and PlGF: two pleiotropic growth factors with distinct roles in development and homeostasis. Cell Tissue Res 314:5-14, 2003

30. Luttun A, Tjwa M, Carmeliet P: Placental growth factor (PlGF) and its receptor Flt-1 (VEGFR-1): novel therapeutic targets for angiogenic disorders. Ann N Y Acad Sci 979:80-93, 2002

31. Luttun A, Tjwa M, Moons L, Wu Y, Angelillo-Scherrer A, Liao F, Nagy JA, Hooper A, Priller J, De Klerck B, Compernolle V, Daci E, Bohlen P, Dewerchin M, Herbert JM, Fava R, Matthys P, Carmeliet G, Collen D, Dvorak HF, Hicklin DJ, Carmeliet P: Revascularization of ischemic tissues by PlGF treatment, and inhibition of tumor angiogenesis, arthritis and atherosclerosis by anti-Flt1. Nat Med 8:831-840, 2002

32. Rakic JM, Lambert V, Devy L, Luttun A, Carmeliet P, Claes C, Nguyen L, Foidart JM, Noel A, Munaut C: Placental growth factor, a member of the VEGF family, contributes to the development of choroidal neovascularization. Invest Ophthalmol Vis Sci 44:3186-3193, 2003

33. Pipp F, Heil M, Issbrucker K, Ziegelhoeffer T, Martin S, van den Heuvel J, Weich H, Fernandez B, Golomb G, Carmeliet P, Schaper W, Clauss M: VEGFR-1-selective VEGF homologue PIGF is arteriogenic: evidence for a monocyte-mediated mechanism. Circ Res 92:378-385, 2003 